\title{
Molecular Cryo-Electron Tomography of Skin
}

\author{
Lars Norlén ${ }^{*}$
}

Department of Cellular and Molecular Biology, Karolinska Institute, Stockholm, Sweden

\begin{abstract}
The three-dimensional structure of skin can be studied at near-native conditions at the molecular level with a new technique called molecular electron tomography of vitreous tissue sections (tissue TOVIS). Its usage is, however, still largely limited by a difficult sample handling procedure. Here we discuss some measures for the efficient application of tissue TOVIS to dermatological research.
\end{abstract}

Keywords: Skin barrier, cryo-electron microscopy of vitreous sections, CEMOVIS, cryo-electron tomography of vitreous sections, TOVIS.

\section{INTRODUCTION}

Presently, major efforts are directed towards unravelling biological mechanisms at the molecular level in skin. Until now these efforts have been hampered by the difficulty in obtaining near-native in-situ data with molecular resolution. Tomography of vitreous tissue sections (tissue TOVIS) has the potential to obtain three-dimensional structural data of biomolecules in their native cellular context with a resolution of a few nanometers. The technique is however still difficult to learn, time consuming and expensive which has limited its present use in dermatological research. The present review aims at pinpointing the major practical difficulties involved in the application of tissue TOVIS to human skin. For a more extensive review of the technical challenges involved, please refer to [1].

\section{CRYO-ELECTRON MICROSCOPY OF VITREOUS TISSUE SECTIONS}

The need for complete specimen dehydration limits the use of conventional electron microscopy (EM). In biological samples water is the main constituent. Tissue dehydration results in loss of non-aqueous biomaterial and aggregation. Further, heavy metal staining is used to increase image contrast. Consequently, it is not the biological material per $s e$, but deposits of contrast agents that are observed [1].

These problems can be circumvented by the use of cryoelectron microscopy of vitreous sections (CEMOVIS) [2, 3]. In CEMOVIS, a biological specimen with a thickness of up to about $200 \mu \mathrm{m}$ [4] is fixed by means of ultra rapid ( 20 ms) cooling (below $-140^{\circ} \mathrm{C}$ ) under high pressure ( 2000 bar) [3]. The high-pressure frozen, vitrified sample is then cut into ultrathin (50-80 nm) sections in a cryo-microtome, and finally observed in a cryo-electron microscope. In this way the nanostructure of skin can be studied in its native fully hydrated state, without chemical fixation or staining.

Recently, CEMOVIS has helped address several key questions in Dermatology such as membrane processing

\footnotetext{
*Address correspondence to this author at the Department of Cellular and Molecular Biology (CMB), Karolinska Institute, Stockholm, Sweden; Tel: 0046 (0)8524 87658; E-mail: lars.norlen@ki.se
}

during skin barrier formation $[5,6]$, keratin intermediate filament structure and function [7] and desmosomal cadherin organisation [8].

Much detail in cryo-electron micrographs of vitreous tissue sections is however obscured by superposition of biomaterial in the section thickness direction. This problem can, however, be overcome if CEMOVIS is combined with tomography (TOVIS, tomography of vitreous sections).

\section{ELECTRON TOMOGRAPHY}

In electron tomography (ET) an object is threedimensionally (3D) reconstructed from a series of electron microscopy images recorded at different angles [1]. 3D reconstruction is usually performed using a mathematical technique called back-projection [9]. Single-axis tilting is the most common data acquisition geometry. Here the specimen plane is rotated along a single axis. The rotation angle is usually contained within -60 to 60 degrees. The missing region in a single axis $+/-60$ degrees tilt series results in a substantial loss of resolution along the beam direction in the $3 \mathrm{D}$ reconstruction. For $\mathrm{a}+/-30$ degrees missing region in a single axis tilt series the resolution is about $50 \%$ lower in the beam direction [10].

\section{CRYO-ELECTRON TOMOGRAPY OF VITREOUS TISSUE SECTIONS}

Successful attempts at performing TOVIS were first reported in 2002 [11-17]. The main obstacle towards attaining molecular resolution was tilt-series image alignment. However, Masich et al. have developed a new method for the deposition of fiducial markers directly onto the vitreous skin sections, allowing for a tilt series alignment error of $<\operatorname{lnm}[16]$.

\section{Complementary Molecular Immuno-Electron Tomography}

CEMOVIS and TOVIS are costly, time consuming and technically demanding. Freeze-substitution ET may therefore constitute a complement to tissue TOVIS. The main advantage of freeze-substitution ET is that higher electron doses are tolerated than for TOVIS. Freeze-substitution ET is also much less technically demanding. Further, freeze-substitution is compatible with immuno-labeling. This consequently permits 
immuno-ET, where the antibodies themselves binding to their antigen can be directly reconstructed [1].

\section{TOVIS SAMPLE PREPARATION}

Sample compression during cutting of vitreous tissue sections constitutes a drawback with TOVIS [1]. When interpreting ET reconstructions it is therefore necessary to compare biological structures situated in different orientations relative to the sectioning direction. Performing this could, however, be difficult for oriented structures such as epidermal desmosomes [1].

To minimize section compression the diamond knives must be kept scrupulously clean. The optimal cutting feed has been reported to be between 50 and $80 \mathrm{~nm}$ [18].

Other cutting artifacts are crevasses, chatter and knife marks [19]. Crevasses, i.e., local section fractures oriented parallel to the knife-edge and penetrating the section from one side, can be minimized if sections are cut with a feed of less than $80 \mathrm{~nm}$ [18]. Chatter, i.e., a periodic variation in section thickness along the cutting direction because of irregular compression during cutting, is another drawback with TOVIS. It increases section compression yielding locally varying section thickness. Knife marks, i.e., section surface deformations originating from the finite sharpness of the knife-edge [19], are omnipresent on vitreous sections. In our experience, knife marks per se do not constitute a significant practical problem for TOVIS [1].

\section{CONCLUSIONS}

A major obstacle towards the advancement of Dermatology is the lack of a molecular understanding of skin. Molecular tissue TOVIS can, however, now be used to study the native molecular organization of skin with at a few $\mathrm{nm}$ resolution in-situ. The use of tissue TOVIS in dermatological research is today fore mostly limited by its high cost and low yield because of its difficult to learn sample handling procedure.

\section{REFERENCES}

[1] Norlen L, Öktem O, Skoglund U. Molecular cryo-electron tomography of vitreous tissue sections: current challenges. J Microsc 2009; 235: 293-307.

[2] Dubochet J, Adrian M, Chang J-J, et al. Cryo electron microscopy of vitrified specimens. Q Rev Biophys 1988; 21(2): 129-228.
[3] Al-Amoudi A, Chang J-J, Leforestier A, et al. Cryo-electron microscopy of vitreous sections. EMBO J 2004; 23(18): 3583-8.

[4] Studer D, Michel M, Wohlvend M, Hunziker EB, Buschmann M. Vitrification of articular cartilage by high-pressure freezing. J Microsc 1995; 179: 321-32.

[5] Norlén L, Al-Amoudi A, Dubochet J. A cryo-transmission electron microscopy study of skin barrier formation. J Invest Dermatol 2003; 120: 555-60

[6] Al-Amoudi A, Dubochet J, Norlén L. Nanostructure of the epidermal extracellular space as observed by cryo-electron microscopy of vitreous sections of human skin. J Invest Dermatol 2005a; 124: 764-77.

[7] Norlén L, Al-Amoudi A. Stratum corneum keratin structure, function, and formation: the cubic rod-packing and membrane templating model. J Invest Dermatol 2004; 123(4): 715-32.

[8] Al-Amoudi A, Diez DC, Betts MJ, Frangakis AS. The molecular architecture of cadherins in native epidermal desmosomes. Nature 2007; 450: 832-7.

[9] Gilbert PFC. The reconstruction of a three-dimensional structure from projections and its application to electron microscopy. II. Direct methods. Proc R Sot Lond (B) 1972; 182: 89- 102.

[10] Radermacher M. Three-dimensional reconstruction of single particles from random and nonrandom tilt series. J Electron Microsc Tech 1988; 9: 359-94.

[11] Hsieh Ch.-E, Marko M, Frank J, Manella CA. Electron tomographic analysis of frozen-hydrated tissue sections. J Struct Biol 2002; 138: 63-73.

[12] Frank J, Wagenknecht $\mathrm{T}$, McEwen BF, Marko M, Hsieh CE, Mannella CA. Three-dimensional imaging of biological complexity. J Struct Biol 2002; 138: 85-91.

[13] Schwartz C, Nicastro D, Ladinsky MS, Mastronarde D, O'Toole E, McIntosh JR. Cryo-electron tomography of frozen-hydrated sections of eukaryotic cells. Microsc Microanal 2003; 9 (Suppl. 2): 1166-7.

[14] Leis A, Andrees L, Gruska M, Al-Amoudi A, Sartori A, Dubochet J, Baumeister W. Cryo-electron tomography and Xuorescence microscopy of unicellular algae in vitreous cryosections. Microsc Microanal 2005; 11 (Suppl. 2): 330CD.

[15] Hsieh Ch-E, Leith A, Mannella CA, Frank J, Marko M. Towards high-resolution three-dimensional imaging of native mammalian tissue: Electron tomography of frozen-hydrated rat liver sections. J Struct Biol 2006; 153: 1-13.

[16] Masich S, Östberg T, Norlén L, Shupliakov O, Daneholt B. A procedure to deposit fiducial markers on vitreous cryo-sections for cellular tomography. J Struct Biol 2006; 156: 461-8.

[17] Zhang X, Settembre E, Xu C, et al. Near-atomic resolution using electron cryomicroscopy and single-particle reconstruction. Proc Natl Acad Sci USA 2008; 105(6): 1867-72.

[18] Han H-M, Zuber B, Dubochet B. Compression and crevasses in vitreous sections under different conditions. J Microsc 2008; 230(2): 167-71

[19] Al-Amoudi A, Studer S, Dubochet J. Cutting artifacts and cutting process in vitreous sections for cryo-electron microscopy. J Struct Biol 2005b; 150: 109-21.

This is an open access article licensed under the terms of the Creative Commons Attribution Non-Commercial License (http://creativecommons.org/licenses/by-nc/ 3.0/) which permits unrestricted, non-commercial use, distribution and reproduction in any medium, provided the work is properly cited. 